\title{
O TRABALHO DA PESSOA TRANSGÊNERA: POLÍTICAS PÚBLICAS DE IGUALDADE LABORAL ALCANCES E POSSIBILIDADES
}

\author{
THE WORK OF THE TRANSGENDER PERSON: PUBLIC POLICIES OF \\ LABOR EQUALITY SCOPE AND POSSIBILITIES
}

\author{
Miriam Olivia Knopik Ferraz ${ }^{1}$ (i) \\ Nicolas Addor ${ }^{\mathrm{II}}$ (1) \\ Marco Antônio César Villatore ${ }^{\mathrm{III}}$ (1)
}

\begin{abstract}
${ }^{I}$ Pontifícia Universidade Católica do Paraná (PUCPR),

Curitiba, PR, Brasil.

Doutoranda em Direito.
\end{abstract}

E-mail: m.okf@hotmail.com

II Pontifícia Universidade Católica do Paraná (PUCPR),

Curitiba, PR, Brasil.

Doutorando em Direito.

E-mail: nicolasaddor@gmail. com

III Pontifícia Universidade Católica do Paraná (PUCPR),

Curitiba, PR, Brasil

e Universidade Federal de

Santa Catarina (UFSC),

Florianópolis, SC, Brasil.

Doutor em Direito.

E-mail: prof.villatore@gmail.

com

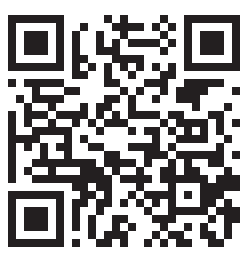

DOI: http://dx.doi. org/10.31512/rdj.v20i37.28

Recebido em: 21.05.2018

Aceito em: 09.01.2020

\begin{abstract}
Resumo: $\mathrm{O}$ artigo tem como objetivo analisar as dificuldades das relaçōes de trabalho que envolvem pessoas transgêneras e também, as formas de inserçáo no mercado de trabalho dito formal. Em um primeiro momento trata-se do estudo de conceitos, da construção da teoria jusfundamental de seus direitos, com o enfoque na fundamentalidade dos direitos sociais das pessoas transgêneras. Em um segundo momento, demonstra-se as principais dificuldades que essas pessoas vivenciam dentro do ambiente laboral, que trazem reflexos e prejudicam diretamente no acesso e permanência. Tais fatores influenciam diretamente e estáo relacionados diretamente a capacitaçáo e ao preconceito. No terceiro momento adentra-se nas políticas públicas que buscam a inclusão, com o enfoque no ambiente laboral. Em um quarto momento adentra-se nas políticas públicas já existentes no Brasil, evidenciadas de forma regional, e exemplifica-se a Argentina, como o país que apresenta diversas proteçóes à pessoa trans. Por fim apresenta-se a proposta do trabalho: uma linha inicial organizacional de políticas públicas a serem realizadas pelo Estado que objetivam o respeito, proteção e promoção a direitos fundamentais das pessoas transgêneras. A construção se dá através do estudo das limitações do trabalho e, assim, traça-se os passos necessários para a construção de políticas públicas voltadas a população em questão, elencando os tipos de políticas públicas a serem realizadas para a efetivação do direito social ao trabalho da pessoa transgênera.
\end{abstract}

Palavras-chave: Pessoas Transgêneras; Igualdade; Mercado de Trabalho; Políticas públicas; Direitos fundamentais.

Abstract: The article aims to analyze the labor difficulties that involve transgender people and also, as forms of insertion in the formal job market. Firstly, it is a study of concepts, the construction of the fundamental theory of their rights, focusing on the fundamental social rights of transgender people. In a second moment, it is demonstrated as main pressures for these people to experience the work environment, that bring reflexes and prejudices directly in the access and permanence. Such events directly influence and are directly related to empowerment and prejudice. There is no moment in the public policies that seek inclusion, with the focus on the work environment. In a fourth moment to penetrate the goals of 


\begin{abstract}
dissemination of data existing in Brazil, the evidence of regional form, and to exemplify an Argentina, as the country that presents several protections to the trans person. Why a work proposal is presented: protection of public policies, protection and promotion of the fundamental rights of transgender people. The construction is due to work practices focused on public life, such as the requirements for the construction of public policies focused on social work. of the transgender person.
\end{abstract}

Keywords: Transgender People; Equality; Labor Market; Public Policies; Fundamental Rights.

\section{Introdução ${ }^{1}$}

Vislumbra-se que o mercado de trabalho pode ser um propulsor para a valorização dos direitos fundamentais. Entretanto, demonstra-se como um ambiente repleto de eventos de exclusão e discriminação, nessa pesquisa, com enfoque as pessoas transgêneras, que em diversas situaçóes, não possuem os seus direitos protegidos, respeitados e valorizados. Assim, é emergencial uma análise das dificuldades laborais que essas pessoas vivenciam, para somente assim, realizar políticas públicas efetivas e direcionadas.

O estudo conceitual a que se propóe passará pela análise teórica da compreensão de direitos fundamentais dos transgêneros, e assim, estuda-se os direitos sociais como direitos efetivamente fundamentais, a multifuncionalidade de todos os direitos fundamentais, o posicionamento do Estado e assim, os seus deveres, o mínimo existencial e as políticas públicas voltadas ao tripé aqui proposto: que possuam como objetivo o respeito, proteção e promoção.

Adentra-se nesse trabalho na posição do Estado como propulsor desse desenvolvimento social, aqui com enfoque nas açóes afirmativas, como um efetivo caminho para a igualdade entre todos. Estuda-se as realidades, através dos meios disponíveis, para elencar-se os problemas enfrentados pelas pessoas transgêneras no mercado de trabalho e assim, construir as possíveis soluções as soluções, no que tange a políticas públicas, direcionando o linear organizacional de ideais de políticas públicas.

O presente estudo se subdivide em dois tópicos: 1. A pessoa transgênera: vivências e proteção laboral, no qual se estuda as conceituaçóes, teorias e as vivências, com o enfoque no ambiente laboral; e 2. Políticas públicas de igualdade laboral para pessoas transgêneras, neste tópico adentra-se nas política públicas já existentes, e nos primeiros passos necessários para a consolidação de tais estruturas de forma geral na realidade brasileira.

1 O primeiro esboço dessa pesquisa foi apresentado em formato de comunicado no I Encontro de pesquisa por/de/sobre Mulheres, após as diversas considerações consolidou-se a pesquisa no presente artigo. (FERRAZ, 2018) 


\section{A pessoa transgênera: vivências e proteçáo laboral}

$\mathrm{O}$ senso comum intitula a transgeneridade como a não identificação com o sexo de nascença ou da certidão de nascimento. (PÚBLICO, 2014). Entretanto, este conceito traz consigo e possui diversas amplitudes e abrangências e resulta do objetivo de "classificação de pessoas" que efetivamente não pertencem e se adaptam a binariedade de gênero (homem e mulher). O exemplo dessa controvérsia é que no ano de 2014 o Supremo Tribunal da Índia reconheceu a existência de um terceiro gênero. (PÚBLICO, 2014)

Com relação ao conceito "transgênero" pontua-se neste estudo que a American Psychological Association demonstra que este seria um termo "guarda-chuva" e é utilizado quando as pessoas expressassem um gênero de forma diversa a condiçóes típicas. Tal expressáo pode se dar por meio de cirurgia de redesignaçáo sexual ou ainda, com vestimentas, corte de cabelo, voz, corpo, dentre outros. (APA, 2011).

Ou ainda, é possível definir como "toda a pessoa envolvida em comportamentos e/ou atividades que de certa forma transgridem a tradição da binariedade de gênero". (LANZ, 2014) Leticia Lanz elenca as categorias abrangidas pelo termo "transgênero" como sendo: 1. Dragqueens e Dragkings; 2. Bigêneros; 3. Pangêneros; 4. Genderbenders; 5. Newhalf; 6. Transexuais; 7. Intersexuados (hermafroditas); 8. Pósgêneros; 9. Genderfuckers; 10. Travestis fulltime; 11.Crossdressers (travestis part-time); 12. Andróginos; 13. Transformistas; 14. Crossplayers; 15. Eunucos; 16. Kathoey (ladyboy) 17. Hjiras; 18. Homens Femininos; 19. Mulheres Masculinas. (LANZ, 2014).

A dificuldade de conceituações de gênero não está só no paradigma da binariedade, mas também, na própria abertura de um terceiro gênero que ainda não exauriria a questáo. Por esse motivo, cabe o destaque da autora Judith Butler que propóe que a ideia de gênero ${ }^{2}$ é concebida de forma externa ao indivíduo e vem como uma imposição para que a pessoa ingresse na sociedade, e está acoplada aos ideais "pertencimento", (BUTLER, 1990, p.122) "transgênero não é uma identidade de gênero, mas a circunstância sociopolítica e cultural que estabelece como transgressão e desvio de conduta a não-conformidade do indivíduo com as normas de conduta de gênero" (LANZ, 2015, p.136). Observa-se então que a ideia de identidade de gênero caminha em muito para ampliar diferenças, distanciamentos e classificaçóes entre as pessoas, e não efetivamente englobá-los como seres humanos.

Diante disso sobserva-se em um primeiro momento o quáo difícil seria o caminho para a igualdade se as pessoas trans fossem classificadas como um terceiro sexo: seria necessário ter uma terceira categoria de banheiro? normas trabalhistas exclusivas para mulheres e que diferenciam gêneros, deveriam ser modificadas e ampliadas a um terceiro

2 Sobre a distinção entre gênero e sexo e teorias de desconstrução: MOORE, 1997 
sexo? Como por exemplo o intervalo do art. 384 da CLT $^{3}$, as restrições do uso máximo da força do art. 390 da CLT, as normas de previdência, a própria licença maternidade e a estabilidade e dentre outras, seriam seriam necessárias normas exclusivas aos transgêneros (e as respectivas subdivisóes)? ${ }^{4}$

Entender as identidades não como um parâmetro de segregação, mas como uma identificaçáo de vivências, lutas e preconceitos, facilitaria na adaptação dessas normativas.

A Constituição de 1988 prevê em diversos enunciados normativos os princípios básicos de defesa e proteçáo dos direitos individuais de qualquer cidadáo, tanto de forma ampliativa como a dignidade humana (Art. 1 ${ }^{\circ}$, III); a própria indistinção entre homens e mulheres (Art. 5 I); como os objetivos da República: garantir uma sociedade livre, justa e solidária (Art. 30, $\mathrm{I}$ ), reduzir as desigualdades sociais e regionais (Art. 30, II), promover o bem de todos sem qualquer tipo de discriminação (Art. $3^{\circ}$, IV); a prevalência dos direitos humanos (Art. 4º, II); a inviolabilidade da intimidade, honra e imagem das pessoas (Art. $5^{\circ}, \mathrm{X}$ ); e a própria penalização de crimes atentatórios aos direitos e liberdades fundamentais (Art. $\left.5^{\circ}, \mathrm{XL}\right)$. De forma mais direcionada ao ambiente laboral temos como fundamento do Estado Democrático de Direito os valores sociais do trabalho (Art. 10, IV), a proteção contra despedida arbitrária e a proibição de diferença salarial (Art. 7º, XXX), de exercício de funçôes e de critério de admissão por motivos de sexo, idade, cor e estado civil. (Art. $7^{\circ} \mathrm{XXXI}$ )

Além disso, tem-se a Lei 9.799/1999 que inseriu na Consolidação das leis do Trabalho "regras sobre o acesso da mulher ao mercado de trabalho", mas que podem e são aplicadas nesse trabalho de forma estendida, já que são fundadas em princípios da não discriminação por sexo, raça, idade e etc. relativa aos assuntos: 1 . publicação de anúncios discriminatório; 2. recusa de emprego, promoçáo ou motivar a dispensa do trabalho; 3. considerar esses fatores como variável determinante para fins de remuneração, formação profissional e oportunidades de ascensão profissional; 4. impedir o acesso ou adotar critérios subjetivos para deferimento de inscriçáo ou aprovação em concursos, em empresas privadas; (Art. 373-A CLT)

Denota-se dessa forma, que os direitos das pessoas transgêneras estão abarcados e assegurados no ordenamento pátrio em nível constitucional e infraconstitucional, uma vez que um dos pilares da sociedade brasileira constitucional é a igualdade independente de critérios como raça, identidade e opçáo sexual, tanto de forma ampla e integrante de todo o sistema, como dentro dos ambientes laborais. Entretanto, tal normativa de valorização e ampliação sistemática de direitos não alcança a realidade das pessoas trans,

3 Atualmente revogado pela Reforma trabalhista Lei no 13.467/2017. (BRASIL, Consolidação das Leis do Trabalho. Art. 384)

4 Ressalta-se que questôes além da esfera laboral também podem ser inferidas, como a aplicação da Lei Maria da Penha as pessoas transgêneras, mas o escopo desse trabalho se limita a questôes juslaborais. Sobre o assunto: (BRASIL, Câmara dos Deputados, 2015) 
tidas como resguardadas a escuridão: afinal, “o escuro da noite é o único espaço permitido às transgêneros" 5 .

Em um primeiro momento evidencia-se a pesquisa "Juventudes na Escola, Sentidos e Buscas: Por que frequentam?” realizada com jovens de 15 a 29 anos, 19,3\% dos alunos de escola pública não gostariam de ter um colega de classe travesti, homossexual, transexual ou transgênero. (ABRAMOVAY; CASTRO; WAISELFISZ, 2015)

Ainda, o Brasil concentra $82 \%$ da evasão escolar de travestis e transgêneros e o tempo de permanência chega a uma média de 4 anos. (ALMEIDA, 2016)

O nível escolar não é o único: o Brasil é o país que mais mata travestis e transexuais no mundo, 144 travestis no ano de 2016 (GRUPO GAY DA BAHIA, 2016). Ainda, a responsabilização dos crimes também é dificultosa, somente em 17\% dos homicídios a pessoas LGBT obteve-se a identificação do criminoso, o que efetivamente resulta em 60 identificaçóes em 343 assassinatos, e ainda, menos de 10\% das ocorrências resultou em processos e efetiva responsabilização e puniçóes.

A pesquisa realizada pela Associação Nacional de Travestis e Transexuais (ANTRA) apontou que $90 \%$ das travestis e transexuais estão se prostituindo no Brasil. (LAPA, 2013), e a Associação das Travestis e Transexuais do Triângulo Mineiro (Triângulo Trans) realizou uma pesquisa em sua regionalidade e consolidou os resultados informando que somente $5 \%$ das travestis e transexuais de Uberlândia "estão no mercado de trabalho dito formal". Por outro lado, 95\%, estão na prostituição.

Os trabalhos que possuem o maior número de pessoas trans e normalmente voltados a identificação com o feminino está como empregadas domésticas, costureiras, balconistas, manicures, cozinheiras, secretárias, recepcionais, faxineiras, babás, cabelereiras, telefonistas etc. e na maioria dos casos fora de regulamentação, instáveis e mal remunerados. (ADELMAN, 2003, p. 84)

A valorização do trabalho digno transpassa diretamente por uma atuação global voltada a inserção laboral e a própria valorização e eficácia dos direitos fundamentais, a discussão da jusfundamentalidade dos direitos sociais ao trabalho em si, e a aplicação desse conjunto as pessoas transgêneras. Há várias divergências entre a doutrina quanto ao entendimento dos direitos sciais como fundamentais, mas em breves palavras ${ }^{6}$ adotarse-á a posição da jusfundamentalidade desses direitos. ${ }^{7}$

Primeiramente aponta-se que a efetiva e grande distinção entre direitos sociais e de liberdade e, em decorrência se são ou não direitos fundamentais, está calcada em

5 Observe a "não concordância" linguística entre o "às" como feminino, e "transgêneros" como masculino, se encaixando perfeitamente à proposição da dissonância da binariedade de gênero. CARVALHO, 2006.

6 Sobre toda a problematizaçáo que essa temática envolve: (HACHEM, 2014)

7 Doutrinadores que defendem e desenvolvem essa posiçáo, destaca-se: Ingo Wolfgang Sarlet, Jorge Reis Novais e Daniel Wunder Hachem. 
"desatenção ou ignorância” principalmente no que tange a ideia de multifuncionalidade dos direitos fundamentais. (NOVAIS, 2010, p. 10-44)

Sobre a temática da multifuncionalidade Robert Alexy (2014, p. 214) explica que os direitos fundamentais possuem "feixes de posiçôes jusfundamentais", ou seja, devese analisar cada direito fundamental como um "direito fundamental como um todo". Por isso, os direitos fundamentais são multifuncionais, ${ }^{8}$ e por isso, não seria possível associar a cada um deles com uma função e a outro não. Observa-se que de cada direito fundamental extrai-se diversos deveres, que efetivamente ensejaram em atitudes estatais.

Jorge Reis Novais aprofunda a temática e defende é que todos os direitos fundamentais possuem diversas funções, de defesa, proteção e respeito, e elas se materializam de acordo com as situações. Assim, eventuais diferenças de regimes jurídicos estão voltadas a essas funções quando materializadas nas situações em concreto, e não como se existissem dois tipos de direitos fundamentais diferentes. (HACHEM, 2014, p.96)

Por esse motivo, não é correto afirmar que há "direitos gratuitos e direitos caros", um dos primeiros argumentos quando se pensa em açóes afirmativas a nível de direitos sociais.

Para alcançar a concretização dos direitos observa-se que em determinado momento da história, todos tiveram ou ainda tem custos e ainda assim, precisam de uma proteção extensiva e progressiva por parte do Estado. Os direitos são interdependentes e indivisíveis, já que se observa que eles possuem “pretensóes híbridas”, e assim, influem em uma multifuncionalidade (CARBONELL, 2010, p. 47)

Assim, o complexo de funçóes dos direitos fundamentais enseja necessidades de proteçáo e prestaçáo, que atingem diretamente o Poder Público com obrigaçóes, mas também e e inclusive, pretensóes direcionadas aos particulares (ALEXY, 2014, p. 249). A prestação se subdivide em: fática e/ou normativa, e essa última possui funções de organização e procedimento. (ALEXY, 2014, p. 196-203; HACHEM, 2014, p. 130)

$\mathrm{O}$ que se observa é que há obrigações de fazer e não fazer, todas conectadas e que se complementam, formando um "complexo de obrigaçóes positivas e negativas", e em muitos casos, é de extrema necessidade que o Estado regulamente e/ou crie estruturas para que haja a efetiva realização e materialização de um direito (PRONER, 2007, p. 24-25)

O direito do trabalho possui uma jurisdição específica, mas está diretamente relacionada com a promoção e valorização de vários outros direitos, que efetivamente constroem uma superestrutura de direitos, fundamentais às pessoas transgêneras.

8 Ingo Sarlet consubstancia com esse entendimento ao tratar que várias das normas de direitos fundamentais exercem duas ou mais funçôes de forma simultânea e assim, "inevitável alguma superposição”. (SARLET, 2008, p. 166). 
Observa-se então, que o direito social do trabalho é um direito evidentemente fundamental. A sua estrutura é formada por feixes de posiçôes jusfundamentais que em diversos aspectos exigem e necessitam de açóes positivas e negativas do estado. $\mathrm{O}$ "direito do trabalho projeta sua eficácia em direção ao [...] Estado e os tomadores de trabalho e empregadores", a grande evidência que destaca-se nesse estudo, é que a este direito é de responsabilidade também dos empregadores a proteção e respeito da eficácia dos direitos fundamentais do trabalhador estabelecida pela CRFB e regulada pelo legislador ordinário. (WANDELLI, 2009, p. 338-339)

Leonardo Wandelli apresenta a classificação do direito ao trabalho em três níveis, quais sejam: 1. direito ao conteúdo próprio do trabalho nas relaçóes assalariadas; 2 . direito ao trabalho nas formas não assalariadas; e 3. direito ao trabalho como primeiro direito fundamental (WANDELLI, 2009, p. 341-362)

Observa-se que os dois primeiros níveis trazem a preocupação com a "possibilidade de trabalho, enquanto o segundo se preocupa com a oportunidade de trabalho digno" (WANDELLI, 2009, p. 402) e o terceiro nível traz o direito do trabalho como "primeira mediação para a satisfação de todas as necessidades dos sujeitos humanos no desenvolvimento de sua corporaliedade”. (WANDELLI, 2009, p. 398)

Materializa-se então essas perspectivas teóricas aos direitos das pessoas transgêneras. Para que seja possível uma das facetas, que é o respeito, é necessária uma atuação ampliativa e que observe diversas pretensóes, como por exemplo o direito ao reconhecimento e a ideia de autodeterminação quanto a identidade.

Em um primeiro momento aparenta ensejar somente a faceta do respeito de seus direitos, uma ação essencialmente negativa do Estado, mas observa-se ao confrontar com a realidade as diversas perspectivas de preconceito realizadas por terceiros que impossibilitam a efetivação de tal direito e portanto, requerem açóes positivas do estado:

1. promoção da informação para a população em geral, órgãos, entidades, empresas, instituiçóes de ensino e etc.,

2. proteção contra intervenção de terceiros, intimamente relacionada a informação, mas também ao fortalecimento da segurança pública e puniçóes devidas, dentre outras.

Ou seja, demonstrou-se que dentro da perspectiva de um direito eminentemente de respeito, de igualdade, reconhecido formalmente como um direito de liberdade, observa-se as diversas facetas que ele enseja, e assim, as diversas possibilidades de atuação Estatal para a efetiva proteção e valorização desses direitos.

Outro exemplo é o próprio direito social ao trabalho da pessoa transgênera que analisado como um todo ensejaria poder-se-ia defender apenas com açóes afirmativas, ou seja, atos positivos, como políticas públicas de acesso, inclusão, permanência. Entretanto, observa-se a outra faceta: a necessidade da proteção negativa, como uma perspectiva do 
direito laboral como liberdade de exercício de profissão, a própria liberdade de escolha da carreia, o que efetivamente não se observa como elencado anteriormente.?

Assim, para a valorização e ampliação de um mínimo dos direitos das pessoas transgêneras, transpassa-se pela valorização, de forma concomitante ao direito ao trabalho. Este direito está diretamente relacionado e interligado à própria liberdade, cidadania e também como uma forma de efetivação dos mais diversos direitos sociais.

Afirma-se então, que os direitos das pessoas transgêneras estão inter-relacionados ao trabalho e este afirma-se como um fator essencial que garante uma vida digna. (GONÇALVES; LOPES, 2013, p.135-139)

No mesmo sentido, afirma-se Ingo Sarlet: "a garantia efetiva de uma existência digna abrange mais do que a garantia da mera sobrevivência física, situando-se, portanto, além do limite da pobreza absoluta." (SARLET; FIGUEIREDO, 2008) Antônio Pedro Albernaz Crespo e Elaine Gurovitz, afirmam que o conceito de pobreza está relacionado a situação em que o "indivíduo, quando comparado a outros, tem menos de algum atributo desejado, seja renda, sejam condiçôes favoráveis de emprego ou poder" (CRESPO; GUROVITZ, 2002) Dessa forma, nessa perspectiva observa-se que a pobreza em sentido lato sensu é vivenciada e estigmatizada pelas pessoas transgêneras, que não possuem a devida proteção e ainda, esta é constantemente dificultada por preconceitos e discriminações.

Ademais, observando uma perspectiva dentro das realidades laborais, há a necessidade de se vislumbrar o direito ao mínimo existencial e sua conceituação, uma vez que este pode ser entendido como patamar para a formação de políticas públicas. Observa-se também que é através desse instituto que pode-se efetivar e trazer ao patamar da mais legítima obrigatoriedade a realização dos direitos como um todo.

Para que se possa vincular uma categoria de direitos ao mínimo existencial, é necessário que as prestações que o Estado possa realizar se demonstrem "indispensáveis à vida digna” (WANDELLI, 2009, p.143). Ademais, o mínimo existencial possui relação essencial com o princípio da dignidade humana, e este, possui feixes a garantia à vida. (HACHEM, 2010, p.211)

Sobre o mínimo existencial destaca-se duas correntes: A primeira defende o instituto de forma restrita afirmando que se deve observar o rol preferencial apresentado na constituição e a segunda vincula a interpretação diretamente ao caso concreto. Restringir a importância dos direitos ao caso concreto é exaurir a proteção fixa que se necessita, principalmente, no que tange ao direito das pessoas transgêneras, uma vez que ela vincularia a realização dos direitos as diferentes formas e possibilidades de interpretação do sujeito intérprete. Algo que poderia ensejar na inaplicabilidade desse direito, diante do

9 Sobre a questáo da (im)possibilidade de escolha laboral da pessoa transgênera: CARVALHO, 2006. 
preconceito enraizado na sociedade brasileira, ou seja, prejudicaria de forma substancial a funcionalidade operacional do instituto. (WANDELLI, 2009, p.143)

Nesse artigo defende-se que os direitos sociais devem ser aplicados de forma IMEDIATA e que estes compóem o mínimo existencial (HACHEM, 2010, p.216). Essa posição é adotada por Ingo Sarlet ao incluir nesse conceito "aspectos essenciais do direito do trabalho e da proteçáo do trabalhador" (HACHEM, 2010, p.214).

No mesmo sentido ampliativo tem-se a posição de Carolina Zancaner Zockun que trata que o trabalho é componente do mínimo existencial, justificando pelo fato de o trabalho estar inter-relacionado com a vida, e ainda, o próprio desemprego impossibilita a sobrevivência do indivíduo. (ZOCKUN, 2010, p. 209-210)

Essas perspectivas teóricas são diretamente aplicáveis e é fácil de se vislumbrar a perspectiva das pessoas transgêneras, a este estudo aduz que ao proteger o trabalho, na perspectiva do acesso, inclusão e manutenção, das pessoas transgêneras, diretamente se protegeria a possibilidade de estas pessoas realizarem e efetivarem as reais escolhas sobre sua profissão e efetivar em conjunto direitos como a vida, saúde, e a própria existência e visibilidade. É preciso permitir a escolha.

Parte desse processo de escolha é entender que iniciativas pontuais tem o poder de transformar e alcançar resultados significativos. O ganho de poder pelos indivíduos, que podem realizar suas escolhas e opçóes efetivamente "é um dos aspectos centrais no processo de desenvolvimento em muitos países do mundo atual”. (SEN, 2000, p. 234)

Dessa forma, "os cidadáos precisam viver e atuar na sociedade na condição de agentes ativos, desenvolvendo as suas capacidades". (ZAMBAM; KUJAWA, 2017, p. 68) Como pensar em empoderamento das pessoas transgêneras quando se vivencia uma realidade de privaçóes de liberdades mínimas?

Ações nos mais diversos âmbitos, como políticas públicas, ações pontuais, reformas legislativas e etc., deverão criar reais oportunidades sociais, e este é o referencial para o entendimento do desenvolvimento das capacidades. (ZAMBAM; KUJAWA, 2017, p.68) O objetivo deve ser promover o desenvolvimento dos indivíduos, e o trabalho é um dos fatores propulsores.

Observa-se que as privações destinadas as pessoas transgêneras estão presentes de forma integral em suas vidas. Para permitir que estas pessoas se tornem agentes ativos de suas vidas, é necessário extirpar as privaçóes de suas liberdades, para que possam realizar as suas próprias escolhas de forma segura e verdadeira. Para tanto, uma das possibilidades é que o Estado realize uma atuação direta para o respeito, promoção e proteção do direito ao trabalho da pessoa transgênera, e a sua atuação estará direcionada a formulação e realização de políticas públicas. ${ }^{10}$

10 Políticas públicas devem ter como fundamento a inclusáo social e principalmente com enfoque no desenvolvimento e na pessoa humana como centro. REYNA, 2014, p. 38. 
Dessa forma, os problemas enfrentados pelas pessoas transgêneras dentro da perspectiva laboral e que precisam ser superados são:

A. Capacitação: esta deve ser entendida de forma ampla abrangendo três nichos diferentes da sociedade:

A.1. as pessoas transgêneras não tem inclusão e acesso igual aos níveis de ensino tanto fundamental, médio, técnico e superior, como ressalvado anteriormente sobre o preconceito e evasão escolar. A.2. não há capacitação, formação e informação efetiva dos próprios professores e da estrutura das escolas (em todos os níveis), para entender a vivência transgênera, ensinar e repreender situações de preconceito e discriminação. É necessário que essa temática seja desenvolvida de forma correta dentro de sala de aula, sendo esta um reflexo de e para a sociedade e concomitantemente um fator determinante para o acesso e permanência no mercado de trabalho; A.3. não há a capacitação, formaçáo e informação dentro das empresas tanto dos gestores das empresas, como de todos os empregados/servidores públicos (FERRAZ, 2018)

B. acesso: a falta de oportunidade é fator determinante para a ausência de pessoas transgêneras em profissóes variadas, como se observa no seguinte relato do fotógrafo e designer gráfico Kaique Theodoro, sobre a própria entrega de documentos diante do momento da contratação:

Quando a gerente, ou supervisora, ou dona da franquia, whatever, viu minha carteira de trabalho com o sexo feminino, jogou na mesa e disse que não tinha como lidar com isso, que náo fazia ideia do motivo de eu ter passado no processo seletivo. Eu peguei a carteira de volta, engoli a raiva e fui embora puto da vida com vontade de pegar ela pelos cabelos. (FÓRUM, 2017)

C. permanência e adaptação: neste patamar tem-se problemas como a divisão de banheiros (Direitos das pessoas Trans Chegam ao STF, 2015), o uso do nome social ${ }^{11}$, e o próprio preconceito $\mathrm{O}$ analista de sistema Cauá Cintra relata como é a vivência da transfobia diária:

Eles não respeitam meu nome social, não respeitam meu gênero, não respeitam nada. Eu trabalho no segundo andar. Os equipamentos do servidor do TI ficam no quarto andar. Eles me obrigam a usar o banheiro do quarto andar para ninguém me veja. Dizem que uma mulher poderia ficar constrangida se eu usasse o banheiro feminino, mas não me permitem usar o masculino. (FÓRUM, 2017).

Dessa forma, diante de toda a problematização que envolve o ambiente laboral e a necessidade de reformulação e paradigmas para alcançar a igualdade laboral, será objeto de estudos as políticas públicas que podem atuar como propulsores do desenvolvimento pessoal das pessoas transgêneras e possibilitar a materialização de forma real de seus direitos. 


\section{Políticas Públicas de igualdade e inclusão no mercado de trabalho}

As políticas públicas relacionadas a direitos fundamentais podem ser divididas em dois grupos, primeiramente as políticas públicas constitucionais essenciais e, em um segundo momento as políticas públicas ditas não essenciais. As primeiras estariam ligadas a elementos constitutivos do mínimo existencial. (FONTE, 2013, p. 201)

Ademais, demonstrou-se nesse trabalho que, os direitos sociais das pessoas transgêneras estão vinculados ao mínimo existencial, e por isso há a legitimação das políticas públicas de igualdade laboral para pessoas transgêneras como essenciais, e uma alternativa para a promoção do desenvolvimento real dos seres humanos.

Amartya Sen aponta que "a expansáo da liberdade é vista, por essa abordagem, como o principal fim e o principal meio do desenvolvimento" (SEN, 2000, p.10). Assim, observa-se que este entendimento está diretamente relacionado a ideia de um constitucionalismo democrático, já que considera como elemento essencial e fundamental do desenvolvimento o "processo de ampliação das liberdades". (PANSIERI, 2016, p. 454)

Dessa forma, o desenvolvimento e realização de políticas públicas, sua formulação e construçáo, devem possuir como justificativa principal o combate às causas de privaçáo de liberdade que impedem que os agentes, aqui as pessoas transgêneras, possam ter uma posição ativa para escolher e exercer suas escolhas. (ZAMBAM; KUJAWA, 2017, p. 65)

Dessa forma, a promoção das políticas públicas, segundo Jorge Reis Novais estará vinculada também aos deveres de respeito, proteção e promoção. (NOVAIS, 2010, p. 257-263)

Forma-se entấo a proposta desse trabalho: os níveis de políticas públicas a serem realizados pelo Estado como forma de amparo ao trabalhador transgênero, quanto ao respeito, proteção e promoção dos direitos fundamentais dessas pessoas (FERRAZ, 2018).

Num primeiro momento, faz-se necessário analisar determinadas iniciativas fundamentais apontados por Luiz Mello e Daniela Maroja (MELLO; MAROJA, 2010) que demonstram estruturalmente como se materializam, formam e se mantém as políticas públicas: Primeiramente é necessário um "marco jurídico" que efetivamente comprove a necessidade de proteção do direito de um determinado grupo; a necessidade de um programa ou plano que contenha: princípios, diretrizes, objetivos, metas e eixos estratégicos claros, para que seja possível a formulaçáo, implementaçáo, o monitoramento e a avaliação das açôes; A necessidade de um órgáo responsável para mediar a elaboração e execução das políticas; Um conselho responsável pelo controle social do programa; e por fim, o planejamento orçamentário que demonstre a possibilidade da realização das açôes propostas no programa/plano. 
Vanice Regina Lírio do Valle também estabelece etapas para o processo sequencial de uma política pública, apesar de algumas diferenças quanto ao conjunto estrutural trazido anteriormente: Num primeiro momento, reconhece-se o dado fático como problema, para, posteriormente, estabelecer uma agenda de priorizaçáo de açóes públicas. Num terceiro momento, formula-se uma política pública, por meio do estabelecimento de uma métrica a ser aplicada a essas possibilidades de ação estatal. Em quarto lugar, escolhe-se a política pública a ser implementada, através das alternativas apontadas na etapa anterior. Em quinto, implementa-se a política pública eleita e, em sexto, analisa-se e avalia-se a política pública executada, onde se dará a diagnose dos resultados obtidos. (VALLE, 2009, p. 39-41)

Dentro dessa perspectiva, atualmente as políticas públicas para população LGBT em geral abrangem somente dois desses critérios, quais sejam: 1. Um órgão responsável, a Coordenação Geral de Promoção dos Direitos de Lésbicas, Gays, Bissexuais, Travestis e Transexuais - LGBT, vinculada à SEDH; 2. Conselho Nacional de Combate à Discriminação e Promoção dos Direitos de Lésbicas, Gays, Bissexuais, travestis e transexuais.

Realizando uma interpretação extensiva é possível considerar o Plano Nacional Brasil Sem Homofobia como abrangente também a questão trans, apesar de possuir disposições em sua maioria superficiais. (BRASIL, Governo Federal. Brasil sem Homofobia, s.d.)

Ainda não existe um marco jurídico direcionado e portanto, efetivo e que traga disposições de proteção trans.

Com relação ao mercado de trabalho tem-se duas políticas públicas regionais que se destacam: Transcidadania da cidade de São Paulo ${ }^{12}$ e o Projeto Damas da cidade do Rio de Janeiro de iniciativa da Coordenadoria Especial da Diversidade Sexual. (PROJETO DAMAS, s.d) Esses projetos têm como objetivo a capacitaçáo técnica e direcionamento para o mercado de Trabalho. Destaca-se que o projeto Transcidadania não foi incialmente uma iniciativa estatal, foi realizado pela Pastoral da Diversidade, o que demonstra a sociedade atuando para a transformação dela mesma. Ressalta-se que infelizmente esses projetos náo possuem alcance em todos os estados ou em um plano nacional.

Para a ampliação desse trabalho para uma perspectiva nacional e com o objetivo de abranger questóes que eles não alcançam, é possível propor uma agenda que, por questóes metodológicas, subdivide-se as políticas públicas aqui propostas em: A. Políticas Públicas de Capacitação; B. Políticas Públicas de Acesso; C. Políticas Públicas de Permanência e Adaptação (FERRAZ, 2018).

A. Políticas Públicas de Capacitação: essas políticas irão funcionar como um efetivo tronco que sustentará as políticas atuais e as futuras. Possui como objetivo principal 
transformar o pensamento de segregação e discriminação. Esse tópico é subdividido em três categorias que objetivam abranger as ideias de formação e informação:

A.1. Capacitaçáo da pessoa transgênera: por meiodo incentivo direto ao acesso e permanência na escola a nível fundamental, médio, técnico e superior. Ademais é possível (e necessário) a ampliação de projetos como o Transcidadania e o Projeto Damas para um alcance nacional. Ressalta-se algumas iniciativas: a Universidade Federal do Paraná no final de 2014 incluiu como ação afirmativa no mestrado em Desenvolvimento Territorial Sustentável cotas de até 5 vagas direcionadas prioritariamente para afrodescendentes, indígenas ou pessoas trans. Ressalta-se que caso as vagas não fossem ocupadas elas retornariam para a ampla concorrência. (Educação e inclusão: UFPR do Litoral tem cota para Travestis e Transexuais, s.d.) Dessa forma, propóe-se a formulação de uma política pública nacional com o olhar de inspiração nas políticas públicas já existentes.

A.2. Capacitação das instituições de ensino (em todos os níveis): o objetivo dessa política é trazer para o ambiente de ensino a vivência transgênera da pessoa transgênera. $O$ ensino sobre diversidade de gênero e repreender situaçóes de preconceito e discriminação em face dos transgêneros. ${ }^{13}$ É necessário que essa temática seja desenvolvida de forma correta dentro de sala de aula, tanto pelos professores como pelas próprias instituições de ensino. Ademais, a ideia de autonomia científica parte como pressuposto de que as instituiçóes deveriam possuir um ambiente que concedesse um espaço livre para a possibilidade de pluralismo de ideias e opiniōes, com a prática de respeito mútuo e a negação de atividades reacionárias. (ADDOR, 2018, p. 243-259)

A.3. Capacitação dos empregadores (em todos os níveis): é necessária a formação e informação do ambiente laboral como um todo e visto nas diversas perspectivas, ou seja, nas empresas privadas, públicas, no próprio funcionalismo público, os gestores, e os demais funcionários e empregados. $\mathrm{O}$ objetivo é aproximar a discussão sobre a temática e "tirar das sombras" as pessoas transgêneras. Tal ação possibilitaria que elas não fossem discriminadas em entrevistas, fossem chamadas pelos próprios nomes ${ }^{14}$, sejam incluídas, sejam promovidas e sejam evidenciadas. Um exemplo de um sistema que possui uma abertura e proteção à temática é a Argentina, no qual se observa a primeira iniciativa de formação e valorização do trabalho se deu com a "La Escuela Cooperativa de Trabajo para Travestis y Transexualis Nadia Echazú”, que se desenvolveu por todo o país. Um dos principais marcos matéria foi o Convênio de Cooperação entre o Instituto Nacional contra la Discriminación, la Xenofobia y el Racismo (INADI) e o Ministerio de Trabajo, Empleo y Seguridad Social (MTEySS). (FERRAZ, 2018)

B. Politicas Públicas de Acesso: como destacado anteriormente, somente 10\% dos transexuais estão no mercado de trabalho formal, (LAPA, 2013) e a principal

13 O que se tem hoje é a censura de qualquer menção às categorias "gênero" ou "orientação sexual", especialmente nos planos locais de educaçáo. (Gênero e diversidade sexual nas escolas: uma questáo de direitos humanos, 2015)

14 "Próprio nome" entendido aqui como o nome a que a pessoa transgênera se reconhece, a sua identidade. 
dificuldade relatada é a falta de oportunidade, que em sua grande maioria está pautada em preconceitos, discriminaçóes e na transfobia. Novamente busca-se exemplificar pela Argentina que possui a Lei no ${ }^{\circ}$ 14.783/2015 da Província de Buenos Aires que determina a implementação de cotas para transgêneros e travestis de $1 \%$ nos serviços públicos. No âmbito nacional, observa-se tímidas iniciativas nesse sentido, destaca-se o projeto de Lei 87/2017 do vereador Márcio Martins (PR-CE) (Vereador de Fortaleza propóe cota para transgêneros em concurso, 2017) ${ }^{15}$ no qual propóem cota de $2 \%$ das vagas em concursos públicos municipais a transgêneros e transexuais. Essas iniciativas devem ser estimuladas, ampliadas e valorizadas tanto na administração pública quanto na iniciativa privada. ${ }^{16}$

C. Políticas Públicas de Permanência e Adaptação: não basta apenas alocar as pessoas transgêneras em postos de trabalho, é necessário prover condições para a sua efetivação, e assim, a sua permanência. Nesse sentido ressalta-se a valorização do uso do nome social, a utilização de banheiros, aposentadoria e legislações voltadas exclusivamente as mulheres devem ser observadas (é o nítido caso da maternidade), a este trabalho não se propóe uma mudança extrema de paradigmas e sim, a igualdade entre os seres humanos.

Pensando sobre essa perspectiva igualitária não será necessária a criação de banheiros exclusivamente para transgêneros, criar uma nova categoria de aposentadoria, ou adaptar legislaçóes e criar novas.

O que se propóe é: "C.1. Uso do nome social: cada pessoa possa se identificar como se reconhece, e assim, o uso do nome social em qualquer âmbito laboral, não só na administração pública; C.2. Banheiro: a utilização de todos dos mesmos banheiros" (FERRAZ, 2018), como já se observa na Argentina (NASSIF, 2013), m diversos locais não há banheiros separados e sim "box individualizados" que permite anular eventuais exposiçóes.

As questóes C.3. Aposentadoria e C.4. Legislaçóes exclusivamente voltadas a "mulher" devem ser analisadas com muita cautela, pois essas normatias estão calcadas em fundamentaçóes que carecem de aprofundamentos teóricos, como de conceitos biológicos, discriminaçóes, terceira jornada feminina e fatores histórico culturais. Tais elementos devem ser estudados e examinados de forma sempre a realizar a progressividade dos direitos. Dessa forma, a este estudo propóem-se a necessidade de políticas públicas de fomento ao estudo e desenvolvimento não só no campo teórico jurídico, mas também no científico-prático. (FERRAZ, 2018)

Dessa forma, as políticas públicas voltadas a permanência e manutenção terão, de forma conjunta, o enfoque na capacitação lato sensu, a inclusão da ideia geral de igualdade e superação do binômio de gênero. Em um patamar imediato, se demonstra

15 Destaca-se que o primeiro comentário da referência citada quando esta pesquisa foi realizado foi "tem que tirar esses lixos da sociedade".

16 Para o aprofundamento da temática de açôes afirmativas de cotas, recomenda-se o paralelo as cotas raciais: MOEHLECKE, 2002. 
como necessárias políticas que possibilitem, materializem e efetivamente tragam proteções e promoçóes diferenciadas as pessoas transgêneras. Através desse enfoque inclusivo poderá se superar a muralha de preconceitos que impede a sua real inserção no mercado de trabalho.

\section{Consideraçóes finais}

O primeiro passo para se pensar em políticas públicas de inclusão laboral da pessoa transgênera, é efetivamente conhecer qual o problema que se está lutando contra. Observou-se nesse estudo que pensar os seres humanos como uma única categoria é mais adequado do que formular novos gêneros, principalmente diante das diversas particularidades e possibilidades da vivência do gênero pelos seres humanos, é o que se demonstrou por meio do confronto da terminologia de "guarda-chuva" de Leticia Lanz, e a possibilidade do "terceiro sexo" e a estrutura binária de gênero.

Em um segundo momento estudou-se a estruturação dos direitos fundamentais sociais ao/do trabalho da pessoa transgênera, ressaltando-se que a proteção ampliativa dos institutos constitucionais e infraconstitucionais não se demonstra suficiente para proteger a população transgênera. O que efetivamente não ocorre é a superação de discriminaçóes, trasnfobia e preconceitos.

Demonstrou-se também, através dos estudos das perspectivas de multifuncionalidade dos direitos fundamentais que os direitos juslaborais das pessoas transgêneras são direitos fundamentais, são componentes do do mínimo existencial e também, possuem aplicabilidade imediata.

Demonstrou-se os problemas enfrentados pelas pessoas transgêneras no ambiente laboral, abarcados em três grandes grupos: A. Capacitação: A.1. As pessoas transgêneras não tem inclusão e acesso igual aos níveis de ensino; A.2. Não há capacitação, formação e informação efetiva dos próprios professores e da estrutura das escolas (em todos os níveis), para enfrentar situaçóes de preconceito e discriminação; A.3. Não há a capacitação, formação e informação dentro das empresas; B. Acesso e C. Permanência e Adaptação.

Adentrou-se então efetivamente nas políticas públicas direcionadas a igualdade laboral das pessoas transgêneras, entendidas como essenciais e facilitadoras para o fim das privaçóes de liberdade e a valorização da condição de agente livre.

Propôs-se 3 grandes estruturas necessárias para a construção de políticas públicas que efetivamente materializem direitos: A. Políticas Públicas de Capacitação: A.1. Capacitação da pessoa transgênera, A.2. Capacitação das instituiçóes de ensino (em todos os níveis) e A.3. Capacitação dos empregadores (em todos os níveis); B. Políticas Públicas de Acesso; C. Políticas Públicas de Permanência e Adaptação: C.1. Uso do nome social, C.2. Banheiro e as questóes C.3. Aposentadoria e C.4. Legislações exclusivamente voltadas 
a "mulher". Demonstrou-se que as duas últimas dependem de estudos aprofundados e a total reestruturarão de institutos a muito consolidados, fato que ensejará uma política pública de ensino e pesquisa.

Dessa forma, o presente estudo apresentou patamares iniciais para um pensar políticas públicas realmente inclusivas para as pessoas transgêneras. O objetivo principal desse estudo é fomentar o diálogo e a construção de uma sociedade náo calcada em discriminações, e sim, que realmente possibilite que os indivíduos se desenvolvam de forma livre, formando uma sociedade plural, justa e igualitária.

\section{Referências}

ABRAMOVAY, Miriam; CASTRO, Mary Garcia; WAISELFISZ, Júlio Jacobo. Juventudes na Escola, Sentidos e Buscas: Por que frequentam?”. Brasília-DF: Flacso - Brasil, OEI, MEC, 2015.Disponível em: http://flacso.org.br/files/2015/11/ LIVROWEB_Juventudes-na-escola-sentidos-e-buscas.pdf. Acesso em: 20 abr. 2018.

ADDOR, Nicolas. A liberdade científica como requisito para um Estado democrático. In: Janaína Maria Bettes; José Osório do Nascimento Neto; Luiza de Araújo Furiatti; Maria Augusta Oliveira de Souza. (Orgs.). Justiça e democracia. Curitiba: Íthala, 2018, p. 243-254.

ADELMAN, Miriam. Travestis e transexuais e os outros: identidade e experiências de vida. In: Gênero. Niterói: EdUFF, v. 4, n. 1, 2003.

ALEXY, Robert. Teoria dos direitos fundamentais. Tradução Virgílio Afonso da Silva. 2. ed. São Paulo: Malheiros, 2014.

ALMEIDA, Aline. Diário de Cuiabá. In: Evasão escolar entre travestis é bem maior. 2016. Flacso Brasil. Disponível em: http://flacso.org.br/?p=15833. Acesso em: 20 mar. 2018.

APA- American Psychological Association. Answers to your questions about transgender people, gender identify and Gender Expression. Washigton-DC: American Psychologinal Association, 2011. Disponível em: http://www.apa.org/topics/lgbt/transgender.aspx. Acesso em: 20 abr. 2018.

BRASIL. Câmara dos Deputados. Lei Maria da Penha poderá valer para transexuais e transgêneros. 2015. Disponível em: https://goo.gl/H8C5dk. Acesso em: 20 mar. 2018.

BRASIL. Consolidação das Leis do Trabalho. Disponível em: http://www.planalto.gov.br/ ccivil_03/decreto-lei/Del5452.htm. Acesso em: 20 mar. 2018.

BRASIL. Constituição da República Federativa do Brasil. Disponível em: http://www. planalto.gov.br/ccivil_03/constituicao/constituicao.htm. Acesso em: 20 mar. 2018. 
BRASIL. Decreto $n^{\circ}$ 8.727, de 28 de abril de 2016. Disponível em: https://goo.gl/ QEq4Vd. Acesso em: 20 mar. 2018.

BRASIL. Decreto $n^{\circ} 8.727$, de 28 de abril de 2016. Disponível em: https://goo.gl/ QEq4Vd. Acesso em 26 de março de 2018

BRASIL. Governo Federal. Brasil sem homofobia. Disponível em: http://bvsms.saude. gov.br/bvs/publicacoes/brasil_sem_homofobia.pdf. Acesso em: 20 mar. 2018.

BRASIL. Governo Federal. Brasil sem homofobia. Disponível em: http://bvsms.saude. gov.br/bvs/publicacoes/brasil_sem_ homofobia.pdf. Acesso em: 25 março 2017.

BRASIL. Lei no 8.213, de 24 de julho de 1991. Disponível em: http://www.planalto.gov. br/ccivil_03/leis/L8213cons.htm. Acesso em 20 de abril de 2017

BRASIL. Lei no 8.213, de 24 de julho de 1991. Disponível em: http://www.planalto.gov. br/ccivil_03/leis/L8213cons.htm. Acesso em: 20 abr. 2018.

BUTLER, Judith. Gender Trouble: Feminism and the Subversion of Identity. New York \& London: Routledge, 1990.

CARBONELL, Miguel. Los Derechos Sociales: elementos para una lectura em clave normativa. Cadernos da Escola Judicial do TRT da 4 a região. no 3 de 2010. Disponível: em:https://goo.gl/aJHJuE. Acesso em: 25 mar. 2018.

CARTA CAPITAL. Gênero e diversidade sexual nas escolas: uma questão de direitos humanos. 2015. Disponível em: https://goo.gl/2XHGLP. Acesso em: 22 agos. 2018.

CARVALHO, Evelyn Raquel. "Eu quero viver de dia": Uma análise da inserção das transgêneros no mercado de trabalho. Anais Seminário Internacional Fazendo Gênero 7. Florianópolis: Editora da UFSC, 2006.

CRESPO, Antônio Pedro Albernaz; GUROVITZ, Elaine. A pobreza como um fenômeno multidimensional. RAE-eletrônica, v. 1, n. 2, jul./dez 2002. Disponível em: http://www.scielo.br/pdf/raeel/v1n2/v1n2a03. Acesso em: 22 mar. 2018.

FERRAZ, Miriam Olivia Knopik. Politicas Públicas de Igualdade Laboral para pessoas Transgêneras. Mulheres por mulheres: memórias do I Encontro de Pesquisa por/de/sobre Mulheres [recurso eletrônico] / Eneida Desiree Salgado et al (Orgs.) - Porto Alegre, RS: Editora Fi, 2018.

FONTE, Felipe de Melo. Politicas públicas e direitos fundamentais. São Paulo: Saraiva, 2013.

FÓRUM. Mulheres e homens transexuais relatam rotina de humilhaçôes no acesso ao mercado de trabalho. 2017. Disponível em: https://www.revistaforum.com.br/ transfobia-no-mercado-de-trabalho/. Acesso em: 28 de março de 2018 
GONÇALVES, Heloisa Alva Cortez; LOPES, Maria Helena. A dignidade da pessoa humana e o valor social do trabalho. Revista de Direito Econômico e Ambiental, Curitiba, v. 4, n. 2, p. 129-145, jul./dez. 2013.

GRUPO GAY DA BAHIA. Relatório 2016, Assassinatos de LGBT no Brasil. Disponível em: https://homofobiamata.files.wordpress.com/2017/01/relatc3b3rio-2016-ps.pdf. Acesso em: 20 mar. 2018.

HACHEM, Daniel Wunder. Mínimo Existencial e direitos fundamentais econômicos e sociais: distinçóes e pontos de contato à luz da doutrina e jurisprudência brasileira. In: BACELLAR FILHO, Romeu Felipe; HACHEM, Daniel Wunder (Coord.). Direito público no Mercosul: intervenção estatal, direitos fundamentais e sustentabilidade. Belo Horizonte: Fórum, 2010, p. 205-240.

HACHEM, Daniel Wunder. Tutela administrativa efetiva dos direitos fundamentais sociais: por uma implementação espontânea, integral e igualitária. Curitiba, 2014. 614 f. Tese (Doutorado) - Programa de Pós-Graduação em Direito, Universidade Federal do Paraná.

IBDFAM. Direitos das pessoas Trans Chegam ao STF. 2015. Disponível em: https://goo. gl/qo7Y0f. Acesso em: 25 mar. 2018.

LADO A. Educação e inclusão: UFPR do Litoral tem cota para Travestis e Transexuais. Disponível em: https://goo.gl/ZH8mju. Acesso em: 25 mar. 2018.

LANZ, Letícia. O corpo da roupa: a pessoa transgênera entre a transgressão e a conformidade com as normas de gênero. Uma introdução aos estudos transgêneros. Curitiba: Transgente, 2015.

LANZ, Letícia. O guarda-chuva transgênero. In: Letícia Lanz comenta Dia da Visibilidade Transgênera: 'Queremos chamar atenção para quem vive no armário'. Nlucon. 2014. Disponível em: http://www.nlucon.com/2014/03/leticia-lanz-comentadia-da.html. Acesso em 20 abr. 2018.

LAPA, Nádia. O preconceito contra transexuais no mercado de trabalho. 2013. Disponível em: https://goo.gl/KYE9cP. Acesso em: 25 mar. 2018.

MELLO, Luiz; MAROJA, Daniela. Políticas Públicas para população LGBT no Brasil: um mapeamento crítico preliminar. Revista Fazendo Gênero, n. 9. 2010

MOEHLECKE, S. Ação Afirmativa: história e debates no Brasil. Cadernos de Pesquisa, São Paulo, n.117, p.197-217, nov. 2002.

MOORE, Henrietta, Compreendendo sexo e gênero. Trad. Júlio Assis Simóes. Londres: Routledge, 1997, p. 813-830. Disponível em: http://e-lam.net/moodle/course/view. php?id=10. Acesso em: 20 abr. 2018. 
NASSIF, Luis. Transexualidade e a questão do terceiro banheiro. Nassif online. 2013. Disponível em: http://advivo.com.br/node/1256517. Acesso em: 20 mar. 2018.

NOVAIS, Jorge Reis. Direitos sociais: teoria jurídica dos direitos sociais enquanto direitos fundamentais. Coimbra: Coimbra, 2010.

O PÚBLICO. Índia torna legal a existência de um terceiro género. Público. 15 de Abril de 2014. Disponível em: https://goo.gl/7QoR1X. Acesso em: 20 abr. 2018.

PANSIERI, Flávio. Liberdade como desenvolvimento em Amartya Sen. Constituição, Economia e Desenvolvimento. Revista da Academia Brasileira de Direito Constitucional, Curitiba, v. 8, n. 15, jul./dez. 2016.

PREFEITURA DE SÃO PAULO. Projeto Reinserção Social Transcidadania, Objetivo. Disponível em: https://goo.gl/YFAjBo. Acesso em: 25 mar. 2018.

PROJETO DAMAS, O que é? Disponível em: http://cedsrio.com.br/projeto-damas-oque-e.php. Acesso em: 25 mar. 2018.

PRONER, Carol. Sistema Internacional de Proteção de Direitos Humanos: A Efetividade dos Direitos Econômicos Sociais e Culturais. Caderno da Escola de Direito e Relaçôes Internacionais da UniBrasil. n. 07, jan./dez. 2007.

REYNA, Justo José. La reforma de la Administración Pública local para la tutela de los derechos fundamentales en el siglo XXI. A\&C - Revista de Direito Administrativo \& Constitucional, Belo Horizonte, ano 14, n. 56, p. 35-89, abr./jun. 2014.

SARLET, Ingo; FIGUEIREDO, Mariana. Reserva do possivel, minimo existencial e direito à saúde: algumas aproximaçóes. 2008. Disponível em: http://www.revistadoutrina. trf4.jus.br/index.htm?http://www.revistadoutrina.trf4.jus.br/artigos/edicao024/ingo_ mariana.html. Acesso em: 25 mar. 2018.

SEN, Amartya. Desenvolvimento como liberdade. Tradução de Laura Teixeira Motta. São Paulo: Companhia das letras, 2000.

VALLE, Vanice Regina Lírio do. Politicas públicas, direitos fundamentais e controle judicial. Belo Horizonte: Fórum, 2009.

VEREADOR de Fortaleza propóe cota para transgêneros em concurso. G1. 2017. Disponível em: https://goo.gl/Vh79H1. Acesso em: 20 mar. 2018.

WANDELLI, Leonardo. Direito do Trabalho como direito humano e fundamental: Elementos para sua fundamentação e concretização. Curitiba, 2009. $431 \mathrm{f}$. Tese (Doutorado em Direito) - Programa de Pós-Graduação em Direito, Universidade Federal do Paraná. 
ZAMBAM, Neuro José Zambam; KUJAWA, Henrique Aniceto. As políticas públicas em Amartya Sen: condição de agente e liberdade social. Revista Brasileira de Direito, Passo Fundo, v. 13, n. 1, p. 60-85, jan./abr. 2017.

ZOCKUN, Carolina Zancaner. A intervenção do Estado na ordem social e o direito ao trabalho. In: SPARAPANI, Priscilia; ADRI, Renata Porto (Coords.). Intervenção do Estado no dominio econômico e no dominio social: homenagem ao Professor Celso Antônio Bandeira de Mello. Belo Horizonte: Fórum, 2010. 